\title{
Modification Of Various Product Pipeline System: Optimization and Scheduling
}

\section{H. E. Mohamed*1, M.E. Awad ${ }^{1}$, S. A. Aly ${ }^{1}$}

${ }^{1}$ Petroleum Refinery and Petrochemical Engineering Department, Faculty of Petroleum and Mining Engineering, Suez University, Suez, Egypt

*Corresponding author, Email: hodaelsayed2223@yahoo.com

\section{ABSTRACT}

The optimal scheduling system of multi product pipelines is benefited to improve the economy and safety transportation. This paper addresses how to optimize detailed schedules of a multi-product pipeline. The study covers multi fluid pipeline by national pipeline company which is $130 \mathrm{Km}$. We concern with batching of (Gas oil, Jet fuel, Naphtha, Gasoline 80, Gasoline 95) and here comes the problem of contamination of one fluid with another which is leading fluid. This study estimates the volume of mixing zone for each interface by equation of Austin J.E and palfrey J.R, determines contaminated volume cost and storage volume needed for each cycle and assures that transportation is within flat zone and yield minimum value of interface volume providing the optimum multi-product pipeline scheduling.

KEYWORDS: Batch sequences, Inventory management, Multi-product pipeline, Scheduling optimization, Sequential transportation.

\section{INTRODUCTION}

A multiproduct pipeline may carry numerous products in sequence and often has many entries and exit points. A station with tanks which used to discharge products with the pipeline is located at each entry/exit along a pipeline. Shippers and markets limit the delivery/injection operations worked by any station along a pipeline. Making realistic schedules of a multiproduct pipelines is often a challenging task. To fulfil customer requests for products at each station along a pipeline, as well as to ensure the pipeline's safe and seamless operation, dispatchers must manage delivery/injection amounts at all times [1]. Supply chain and logistics operations are now among the most critical activities in companies[2]. Because products are seldom manufactured and consumed in the same area, transportation is a major supply chain driver[3]. The most popular method of transport in the oil industry to transport products from refinery to depot is multi-product pipeline transporting a range of petroleum products. Transportation system of petroleum products through pipelines is one of the most difficult management challenges in the oil industry, with the potential to enhance annual profit by millions of dollars.

Optimization, a multidisciplinary area where Mathematics and Computer Sciences combine, is one of the most dependable decision support tools accessible today. The objective of this effort is to create and solve realistic mathematical models of the issue under study, allowing decision makers to consider a wide range of viable solutions [4]. The use of optimization methods for scheduling is gaining popularity. Because of the cheap running cost of pipelines, oil firms are ready to expand pipeline usage in major consumer markets where demand for oil and its derivatives is strong. Refineries must be linked to local distribution hubs through pipelines. The items should subsequently be distributed to consumer markets. How to track batches in the pipeline that are subject to intermittent operations is a key difficulty in the problem of optimizing detailed schedules of a multiproduct pipeline.

Rejowski and Pinto (2003, 2004) present a discrete-time, discrete-volume MILP (Mixed Integer Linear Programming) problem for a single pipeline with one source and multiple destinations. Schedules are 
optimized in terms of batch transitions, inventory costs, and pumping costs per unit volume [5][6]. Rejowski and Pinto (2008) transform their previous work into a continuous-time formulation by introducing a variable time grid. The resulting MINLP (Mixed Integer None-Linear Programming) problem contains bilinear terms in the objective function, as variable cost terms are multiplied by variable step sizes [7].

Cafaro and Cerdá (2004) present a continuous-time MILP formulation for the case introduced by Rejewski and Pinto (2003). Their method overcomes several limitations of the previous method, including the issues regarding problem size and volume discretization[5][8] . Cafaro and Cerdá (2004) deal with this by only considering demand at the end of the scheduling horizon. Moreover, costs that depend on both volume and time are approximated by costs per unit volume.

Cafaro and Cerdá (2012) extend their previous method to solve scheduling problems for mesh structure networks involving up to six pipelines. Although the results look promising, it is unclear how the MILP formulation will scale for larger networks[9]. Cafaro et al. (2015) incorporate nonlinear pumping costs and solve the resulting MINLP problem with outer approximation.

Liang Yongtu, et.al (2012) discovered an optimization model for a multi-product pipeline with a known delivery need and operating plan for each off-take point. The main objective of this optimization model is to minimize the total pumping operation coast by taking into account not only the energy equilibrium constraint, the maximum and minimum suction as well as discharge pressure constraints of pump stations, and pressure limitations at special elevation points, but also regional differences in electricity costs all along pipeline. [10]

The dynamic programming method is applied to solve the modern and to find the optimum pump configuration.

\subsection{PROBLEM DESCRIPTION}

The system under consideration consists of a single pipeline that connects a refinery to a distribution center. The refinery generates a variety of oil products, and the distribution center is in charge of supplying these products to the local market. [11].

The study covers multi fluid batching trough National Pipeline Petroleum Company (PPC) which is 130 $\mathrm{km}$. we can concern with batching of (Gas oil, Jet fuel, Naphtha, Gasoline 80, Gasoline 95. When multiple batches are conveyed without separation devices, the contaminated products are inevitably generated between any two adjacent batches under the diffusion action of convection and turbulent. One of the major technologies of multiproduct pipelines is the tracking and management of contaminated products. However, the characteristics, technological processes, and management of contaminated products are challenging, particularly in regions with complex topography and considerable elevation differences. In general, polluted products cannot be sold as qualified products and must be treated by blending or refining, incurring additional operating costs for petroleum companies.[1]

The majority of prior work has focused on two elements of controlling the growth of contaminated products: optimizing batch sequencing and incorporating processing limitations into mathematical models. Aiming for batch sequencing and detailed scheduling of branch pipeline networks, for example. Inventory costs are proportional to the stored amounts of products in all subsystems as well as to the time these remain in the tanks for all systems. Moreover, each locality is represented by an inventory cost coefficient. Pumping costs are proportional to the amount of product sent by the refinery and to the distance it must cover along the pipeline. Pumping cost coefficients depend on the distances of the depots from the refinery. Moreover, it becomes very important to define a distribution schedule that considers time periods of intensive energy consumption[11] Given the size and dynamics of pipeline networks, planning and scheduling network operations is quite complicated. 
Develop a fast and generic method for creating feasible and good schedules for multi-product oil pipeline networks with known supply and demand. A schedule should describe a list of batch injections for each pipeline, specifying batch volumes, product types, start and end times, and flow rates. Schedules should be feasible and good, i.e., operational restrictions on tank levels and flow rates must be obeyed, and operational costs related to pumping energy and trans-mix volumes should be minimized.

\section{MATHEMATICAL MODEL}

This research presents a model for the pipeline transportation of different grades of petroleum products that are sent in the same pipeline as it is cost effective, which is known as batching. [12]

- Step (1): Calculation of viscosity-blending index of the blend.

In the petroleum industry, empirical or proprietary blending equations are common. The best known are the double-logarithmic equation of Refutas. The Refutas equation calculates the viscosity, of the binary blend from viscosities and weight fractions of the components by introducing the so-called viscosity blending index.

$$
\text { VBIi }=\{14.534 \times \ln [\ln (v i+0.8)]\}+10.975
$$

Then, the blend viscosity is calculated as,

$$
\text { VBI Blend }=[\mathrm{XA} \times \mathrm{VBIA}]+[\mathrm{XB} \times \mathrm{VBlB}]+\ldots+[\mathrm{Xn} \times \mathrm{VBIn}]
$$

Finally determine the viscosity of the blend in centistokes (cst), by using the invert of Eq. (1)

$$
\text { vBlend }=\exp \left[\exp \left(\frac{V_{\text {BI Blend }-10.975}}{14.534}\right)\right]-0.8
$$

\section{- Step (2): Calculation of velocities of the blend at different discharge rate.}

Assume that flow rate $(\mathrm{Q})$ and calculate the values of the velocities corresponding to each value of flow rate (Q) from Eq. (4):

$$
\mathrm{U}=\frac{\mathrm{Q}}{\mathrm{A}_{\mathrm{i}}}
$$

\section{- Step (3) Calculation of Reynold's. No}

*To calculate the Reynold's No., we should use Eq. (5):

$$
\mathrm{Re}=\frac{\left(\mathrm{U} \times \mathrm{Di} \times 10^{6}\right)}{v \text { Blend }}=\frac{\rho \cdot \mathrm{v} \cdot \mathrm{di}}{\mu}
$$

\section{- Step (4): Calculation of the interphase length}

Austin and Palfrey (1964) derived two equations, for calculation the contamination length based on critical Reynolds Number.

-If Reynolds number is above the critical value in the turbulent region, then (Equation 6)

$$
\begin{aligned}
& \text { For } \operatorname{Re}>10000 \exp (1.52 \sqrt{\mathrm{d}}) \\
& C=11.75 \operatorname{Re}^{-0.1} \sqrt{\mathrm{dL}}
\end{aligned}
$$

When Reynolds number is below the critical value in the turbulent regime, then (Equation 9).

$$
\begin{array}{ll}
\text { For } \operatorname{Re} \leq 10000 \exp (1.52 \sqrt{\mathrm{d}}) & \text { Eq. (8) } \\
\mathrm{C}=18420 \mathrm{Re}^{-0.9} \sqrt{\mathrm{dL}} \exp (1.21 \sqrt{\mathrm{d}}) & \text { Eq. (9) }
\end{array}
$$


- Step (5): Calculation of the interface volume "the volume of contamination"

To calculate the interface volume or the volume of contamination, the following equation is used:

$$
\mathrm{V}=\mathrm{C} \times \mathrm{Ai}
$$

- Step (6): Calculation of the Major losses • Friction losses•(Hf,):

Eq. (10)

When any fluid flows through a pipe, the pressure continuously drops in the stream wise direction because of friction along the walls of the pipe. It is common to express this pressure drop in terms of an irreversible head loss, the loss dependent on type of pipe, number and type of pipe fittings, flow rate, and nature of the liquid. The friction head is proportional to the square of the flow rate. The Darcy-Weisbach equation links the frictional head loss - or pressure loss - over a given length of pipe to the average velocity of the fluid flows. Henry Darcy and Julius Weisbach inspired the equation's name. The Darcy friction factor is a dimensionless friction factor in the Darcy-Weisbach equation. This is also known as the Darcy-Weisbach or Moody friction factor. The Darcy friction factor is four times that of the Fanning friction factor, and should not be confused with it. Head loss can be calculated with:

* To calculate the head losses by using Darcy-Weisbach equation pipe friction formula given by (equation 11)

$$
\mathrm{h}_{\mathrm{f}}=\mathrm{f}_{\mathrm{d}} \times \frac{\mathrm{L}}{\mathrm{Di}} \times \frac{\mathrm{U}^{2}}{2 \mathrm{~g}}
$$

* For a laminar flow $(\operatorname{Re}<2,300)$ inside a horizontal pipe, the frictional factor is simply:

$$
\mathrm{f}_{\mathrm{d}}=64 / \operatorname{Re}
$$

*If the pipe flow is turbulent $(\operatorname{Re}>4,000)$ determined empirically and is tabulated in tables or charts.

Many researchers, as referred by Smith (1990), adopt a modification of the Colebrook-White equation, (13)

$$
\frac{1}{\sqrt{\mathrm{f}}}=-2 \log \left(\frac{\varepsilon}{3.7 \mathrm{~d}}+\frac{2.825}{\operatorname{Re} \sqrt{\mathrm{f}}}\right)
$$

- Step (7): Calculating the value of the total head losses from Eq. (14)

$$
\mathrm{H}_{\mathrm{t}}=\mathrm{H}_{\mathrm{f}}+\mathrm{H}_{\mathrm{m}}+\mathrm{H}_{\mathrm{s}}
$$

Where $\mathrm{Hm}$ is the minor losses equal to 0.15 head losses and static head (Hs) equal to 50 meters.

\subsection{Case Study}

In this section the proposed mathematical model is tested on five multiproduct pipelines handled in Suez Pipelines Company in Egypt as shown in fig. (1). 


\begin{tabular}{|c|c|c|c|c|c|c|c|c|}
\hline $\begin{array}{c}\text { Gas Oil } \\
\text { (P1) }\end{array}$ & $\begin{array}{c}\text { Jet Fuel } \\
\text { (P2) }\end{array}$ & $\begin{array}{c}\text { Naphtha } \\
\text { (P3) }\end{array}$ & $\begin{array}{c}\text { Gasoline } \\
\mathbf{8 0}(\mathbf{P 4})\end{array}$ & $\begin{array}{c}\text { Gasoline } \\
\text { 95 (P5) }\end{array}$ & $\begin{array}{c}\text { Gasoline (P4) } \\
\text { (P3) }\end{array}$ & $\begin{array}{c}\text { Naphtha } \\
\text { (P2) }\end{array}$ & $\begin{array}{c}\text { Jas Oil } \\
\text { (P1) }\end{array}$
\end{tabular}

Figure (1) The products sequence

Table (1): Multi product Specifications

\begin{tabular}{|c|c|c|c|}
\hline Product & $\begin{array}{c}\text { Flowrate } \\
\text { (Q/time) } \\
\left(\mathbf{( m}^{\mathbf{3}} / \mathbf{m o n t h}\right)\end{array}$ & $\begin{array}{c}\text { Density (p) } \\
\mathbf{( k g / \mathbf { m } ^ { 3 } )}\end{array}$ & $\begin{array}{c}\text { Viscosity (v) } \\
\text { (c. stock) }\end{array}$ \\
\hline Gas Oil & 120000 & 860 & 4.65 \\
\hline Jet Fuel & 40000 & 790 & 1.52 \\
\hline Naphtha & 60000 & 740 & 0.81 \\
\hline Gasoline 80 & 40000 & 760 & 0.79 \\
\hline Gasoline 95 & 40000 & 720 & 0.69 \\
\hline
\end{tabular}

The product specification is shown in table (1) which include flow rate, density and dynamic viscosity for each product. By using a Pipeline material is Carbon Steel and Wrought Iron, With relative roughness $\xi=$ 0 . 00015', which has a Standard diameter $=18$ " SCHEDULE 40. The relative roughness $\xi / D=0.00015$ / $\left(18^{\prime} / 12^{\prime}\right)=0.0001$, length of pipeline $(\mathrm{L})=130 \mathrm{Km}$. As shown in figure $(1)$ which including four mixing zones.

(1) Zone one: Gas Oil - Jet Fuel,

(3) Zone three: Naphtha - Gasoline 80.
(2) Zone two: Jet Fuel - Naphtha,

(4) Zone four: Gasoline 80 - Gasoline 95.

\section{RESULT AND DISCUSSION}

\subsection{Estimation of viscosity blending}

Table 2 showed that the results calculated from Austin and palfrey equation to estimate the viscosity blending index for each zone. The first mixing zone between Gas Oil and Jet Fuel has viscosity of Blend $\left(v_{\text {Blend }}\right)=2.352$ c.st. Assume the flow rate (Q) from 50 to $300 \mathrm{~m}^{3} / \mathrm{hr}$ and, if Re > Rc, then the type of mixing zone will be at "flat region" and the interface length will be calculated by the equation (7) and , If $\operatorname{Re} \leq \mathrm{Rc}$, then the type of mixing zone will be at "steep region" and the Interface length will be calculated by the equation (8). As showed in table 3 , the critical flow rate is $181 \mathrm{~m}^{3} / \mathrm{hr}$ at a critical $\mathrm{Re}=65000$. So, the mixing zone will be flat region at Re more than 65000 . 
Table (2) The results calculated from Austin and palfrey equation to estimate the viscosity blending index for each zone

\begin{tabular}{|c|c|c|}
\hline Zone no. & Product No. & $\begin{array}{c}\text { Viscosity of the blend } \\
\text { vBlend (C.st) }\end{array}$ \\
\hline Zone 1 & P1, P2 & 2.35 \\
\hline Zone 2 & P2, P3 & 1.03 \\
\hline Zone 3 & P3, P4 & 0.80 \\
\hline Zone 4 & P4, P5 & 0.74 \\
\hline
\end{tabular}

Table (3): Evaluation of the contamination volume for the first mixing zone

\begin{tabular}{|c|c|c|c|c|}
\hline $\begin{array}{c}\text { Flow rate } \\
\text { (Q) } \\
\left(\mathrm{m}^{3} / \mathrm{hr} \text {.) }\right.\end{array}$ & $\begin{array}{c}\text { Velocity } \\
\text { (U) } \\
\text { (m/Sec) }\end{array}$ & $\begin{array}{c}\text { Reynold } \\
\text { No. } \\
\text { (Re) }\end{array}$ & $\begin{array}{l}\text { Contamination } \\
\text { length (C) } \\
\text { (m) }\end{array}$ & $\begin{array}{c}\text { Volume of } \\
\text { contamination } \\
(\mathbf{V}) \\
\left(\mathbf{m}^{3}\right)\end{array}$ \\
\hline 50 & 0.0973 & 12307 & 1411.68 & 203.66 \\
\hline 100 & 0.1946 & 24627 & 756.42 & 109.13 \\
\hline 150 & 0.2919 & 36934 & 525.15 & 75.76 \\
\hline 181 & 0.3488 & 65000 & 447.00 & 64.00 \\
\hline 200 & 0.3892 & 72532 & 405.36 & 58.48 \\
\hline 250 & 0.4865 & 90665 & 331.60 & 47.84 \\
\hline 300 & 0.5838 & 108798 & 281.42 & 40.60 \\
\hline
\end{tabular}

*Similar as Zone 2, Zone 3, Zone 4 is shown in figure $(r)$. 


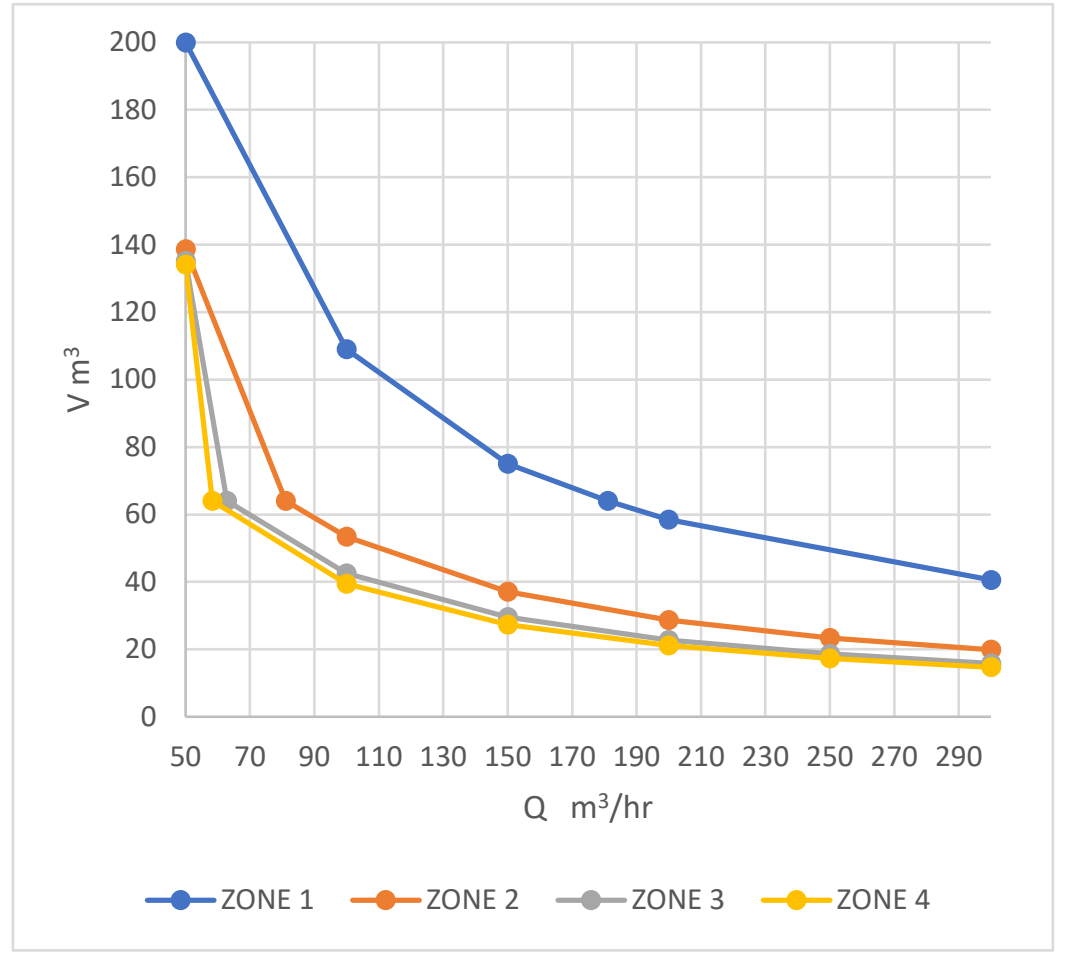

Figure (2) The optimal detailed relation between all mixing zone flow rate(Q) and contamination volume (V) relation

\subsection{The total head losses for the first mixing zone}

By using a Pipeline material is Carbon Steel and Wrought Iron, With relative roughness $\xi=0.00015^{\prime}$, which has a Standard diameter $=18$ " SCHEDULE 40. And the relative roughness $\xi / \mathrm{D}=0.00015 /\left(18^{\prime} / 12^{\prime}\right)$ $=0.0001$. Assume minor losses $(\mathrm{Hm})=0.15 \mathrm{Hf}$ and static head $(\mathrm{Hs})=50$ meter. We obtain Rylond no. from Eq. (5) and Darcy friction factor Eq. (12) and the major losses from Eq. (10), total losses from Eq. (13).

Table (4) evaluation of the total head losses for the first mixing zone

\begin{tabular}{|c|c|c|c|c|}
\hline $\begin{array}{c}\text { Flow rate } \\
\text { (Q/time) } \\
\text { m }^{3} / \mathrm{hr} \text {. }\end{array}$ & $\begin{array}{c}\text { Reynold } \\
\text { No. } \\
\text { (Re) }\end{array}$ & $\begin{array}{c}\text { Darcy } \\
\text { friction } \\
\text { factor } \\
\text { (fD) }\end{array}$ & $\begin{array}{c}\text { Major } \\
\text { losses } \\
\text { (Hf) }\end{array}$ & $\begin{array}{c}\text { Total } \\
\text { losses } \\
\left(\mathbf{H}_{t}\right)\end{array}$ \\
\hline 200 & 49254 & 0.0213 & 49.92 & 107.41 \\
\hline 250 & 61573 & 0.0220 & 74.48 & 135.65 \\
\hline 300 & 73881 & 0.0196 & 103.40 & 168.92 \\
\hline 350 & 86201 & 0.0190 & 136.58 & 207.07 \\
\hline 400 & 98520 & 0.0186 & 173.93 & 250.02 \\
\hline 450 & 110828 & 0.0181 & 215.43 & 297.74 \\
\hline 500 & 123135 & 0.0178 & 260.87 & 350.00 \\
\hline 550 & 135467 & 0.0175 & 310.34 & 406.89 \\
\hline 600 & 147775 & 0.0172 & 363.79 & 468.36 \\
\hline
\end{tabular}




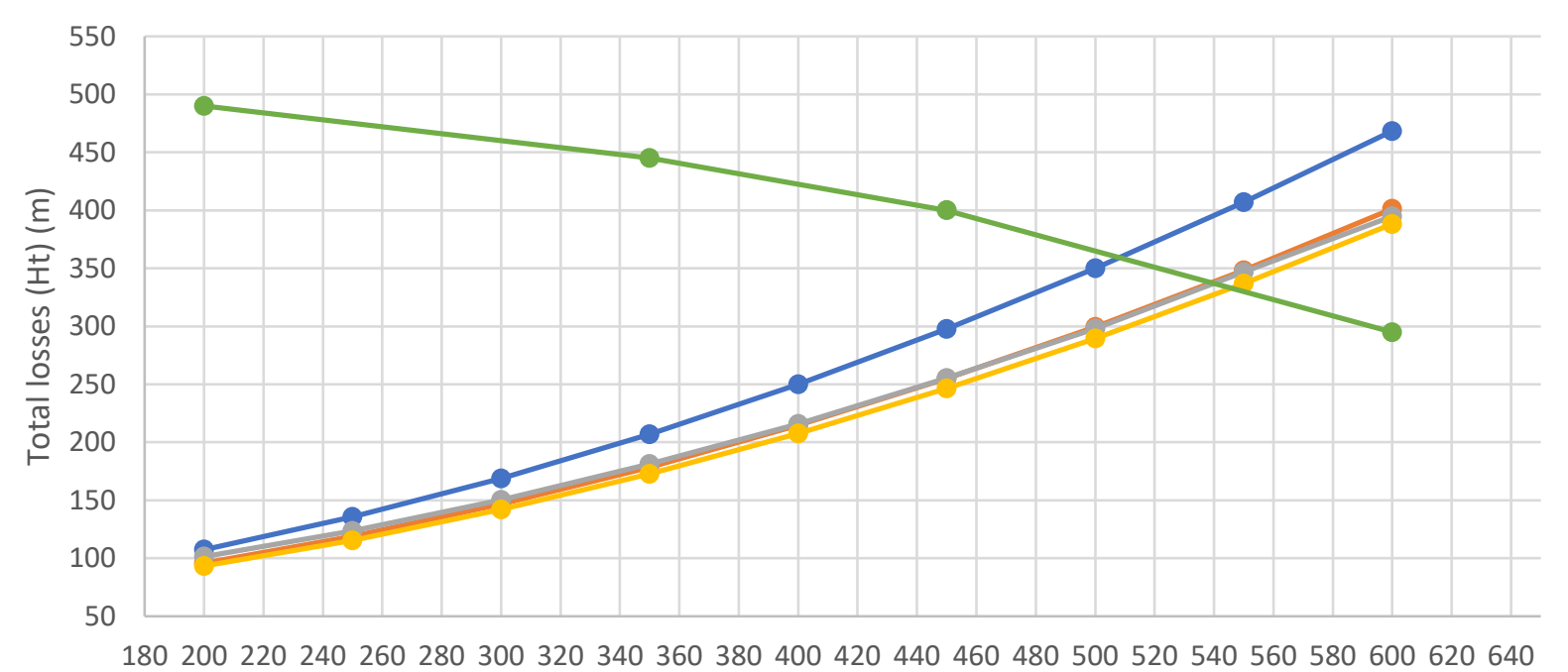

Flow rate (Q) $\mathrm{m} 3 / \mathrm{hr}$.

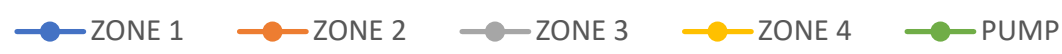

Figure (3) Evaluation the operating point from the intersections between pump curve and curves for each sequence product pipeline

Table (5) The result from intersections between pump curve and curves for each sequence product to indicate the value of flow rate $(Q)$ operational for each mixing zone.

\begin{tabular}{|c|c|c|c|c|c|}
\hline $\begin{array}{l}\text { Mixing } \\
\text { zone } \\
\text { no. }\end{array}$ & $\begin{array}{c}\text { Q } \\
\text { operational } \\
\left(\mathbf{m}^{3} / \mathbf{h r}\right)\end{array}$ & $\begin{array}{c}\text { Reynold } \\
\text { No. } \\
\text { (Re) }\end{array}$ & $\begin{array}{c}\text { Contamination } \\
\text { length }(\mathrm{C}) \\
(\mathrm{m})\end{array}$ & $\begin{array}{c}\text { Volume of } \\
\text { contamination } \\
(\mathrm{V}) \\
\left(\mathrm{m}^{3}\right)\end{array}$ & $\begin{array}{l}\text { Total } \\
\text { Head } \\
\text { losses } \\
\text { Ht }_{t}(\mathrm{~m})\end{array}$ \\
\hline Zone 1 & 515 & 126850 & 245.11 & 35.36 & 365.77 \\
\hline Zone 2 & 540 & 433115 & 81.16 & 11.71 & 332.10 \\
\hline Zone 3 & 540 & 558140 & 64.60 & 9.32 & 331.15 \\
\hline Zone 4 & 545 & 607743 & 59.95 & 8.65 & 326.22 \\
\hline
\end{tabular}

\subsection{The Sequence operation at No. of Cycles}

Table (6) Price of product $\$ / \mathbf{m}^{3}$

\begin{tabular}{|c|c|}
\hline Product & Price $\mathbf{\$} / \mathbf{m}^{\mathbf{3}}$ \\
\hline Gasoline 80 & 780 \\
\hline Naphtha & 810 \\
\hline Gasoline 95 & 870 \\
\hline Jet fuel & 980 \\
\hline Gas oil & 720 \\
\hline
\end{tabular}


At One cycle, the sequence operation $[1,2,3,4,5,4,3,2,1]$ and the operation at storage tanks Quantity loaded $=300000 \mathrm{~m}^{3} /$ month. Table 7 showed the capacity needed for each product as the single tank capacity is $15000 \mathrm{~m}^{3}$.

Table (7) The capacity needed for each product

\begin{tabular}{|c|c|}
\hline Product & Number of Tanks \\
\hline Gas oil & 8 \\
\hline Jet fuel & 3 \\
\hline Naphtha & 4 \\
\hline Gasoline 80 & 3 \\
\hline Gasoline 95 & 3 \\
\hline
\end{tabular}

\subsection{Cost of tanks}

- Cost of tanks $=$ cost of one tank $*$ no of tanks + maintenance fees.

$$
=(488000 \times 21)+(488000 \times 21 \times 0.01)=10350480 \$ \text {. }
$$

- Annual Depreciation cost $=414019 \$$ / year.

Where the Industrial year $=300$ days $=10$ months, number of tanks is 21 , salvage value equal zero, cost of one tank $\left(15000 \mathrm{~m}^{3}\right)=488000$ \$, and maintenance fees Equal to $1 \%$ of the total cost.

Table (8) Values of mixing volume

\begin{tabular}{|c|c|c|}
\hline Mixing zones & Mixing volume $\mathbf{~ m}^{\mathbf{3}}$ & Loss \$/year \\
\hline Gasoil / Jet fuel & 70.72 & 183887 \\
\hline Jet fuel / Naphtha & 23.42 & 39814 \\
\hline $\begin{array}{c}\text { Naphtha / gasoline } \\
\text { 80 }\end{array}$ & 18.64 & 5592 \\
\hline $\begin{array}{c}\text { Gasoline 80 / } \\
\text { gasoline 95 }\end{array}$ & 17.23 & 15569 \\
\hline
\end{tabular}

Table (9) Optimal detailed schedule of the cost

\begin{tabular}{|c|c|c|c|}
\hline $\begin{array}{c}\text { No. of } \\
\text { cycles }\end{array}$ & $\begin{array}{c}\text { Capacity } \\
\left(\mathbf{m}^{3} / \mathbf{m o n t h}\right)\end{array}$ & $\begin{array}{c}\text { Cost of } \\
\text { tank } \\
\mathbf{( \$ / Y e a r})\end{array}$ & $\begin{array}{c}\text { Cost of } \\
\text { losses(\$/year) }\end{array}$ \\
\hline $\mathbf{1}$ & 300000 & 414019 & 165234 \\
\hline $\mathbf{2}$ & 150000 & 236582 & 330442 \\
\hline $\mathbf{3}$ & 100000 & 157721 & 495771 \\
\hline
\end{tabular}




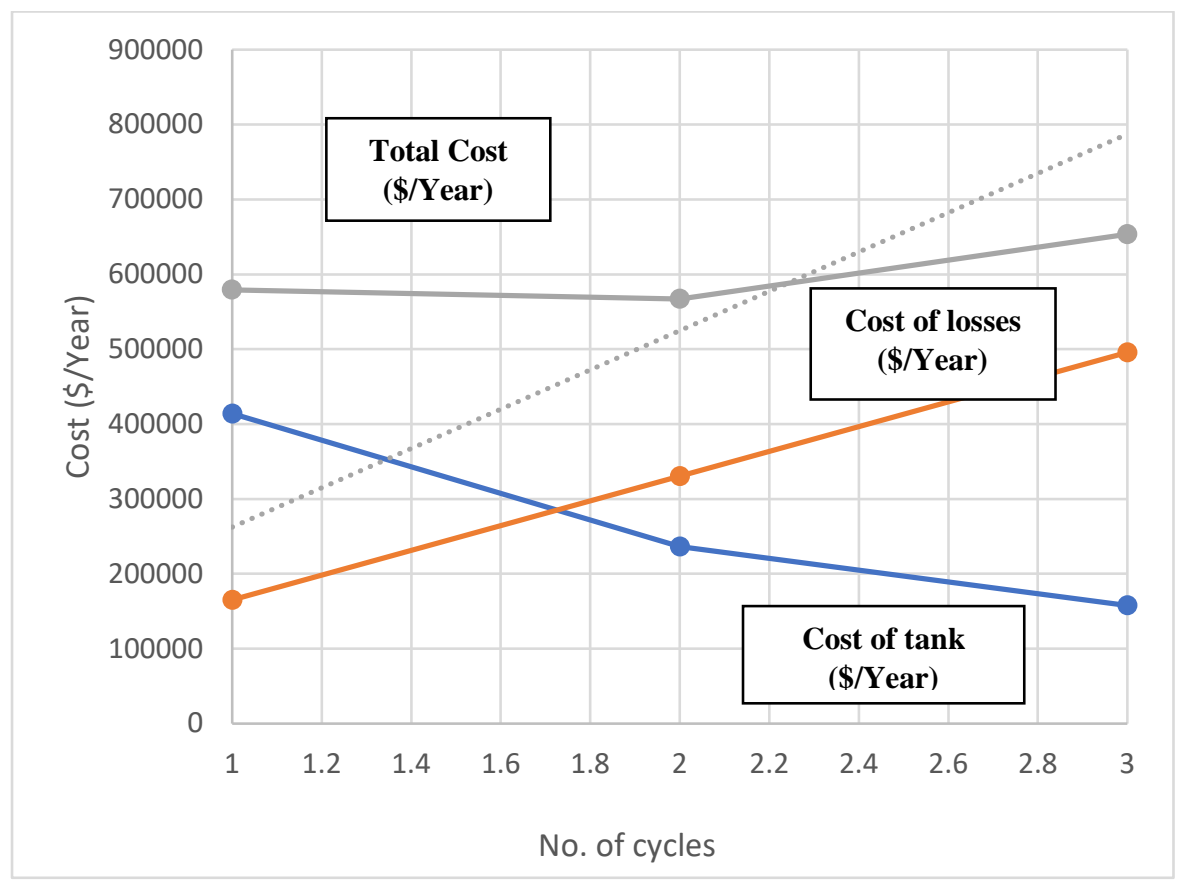

\section{Figure (4) The relation between the cost of tank and cost of total losses of product to obtain the Optimum no. of cycles.}

As showed in Figure (4), The relation between the cost of tank and the cost of total losses of the product, we observed that the optimum no. of cycle is 2 which has the minimum total cost (\$/year).

\section{CONCLUSION}

In this paper, the model solution is the optimization of a multi-product pipeline is different from that of a crude oil pipeline or a natural gas pipeline. Hydraulic conditions along the pipeline change owing to fluid flow and variation of product batches and frequent start/stop operations of each distribution station. Therefore, pump Optimization is required for the entire simulation process. The primary hydraulic calculation is based on actual information, mainly about physical characteristics of the piping system, physical properties of oil, characteristics of pump units, flow rate of the initial station and some basic requirements for pipeline operations. Therefore, the optimal solution to the model can then be obtained. A mathematical model is established to optimize the operation of a multi-product pipeline system, which can provide a guide for pipeline operators. Based on the actual operation data of the Southwestern Multi-Product Pipeline, a mathematical model is developed to calculate the operation cost. After analyzing and contrasting, the optimized cycle is no. 2 due to the minimum tank and losses cost.

\section{REFERENCES}

[1] H. Zhang, Y. Liang, Q. Liao, M. Wu, and X. Yan, "A hybrid computational approach for detailed scheduling of products in a pipeline with multiple pump stations,” Energy, vol. 119, pp. 612-628, 2017.

[2] R. Sahraeian, "Capacitated multimodal structure of a green supply chain network considering multiple objectives,” Int. J. Eng. Trans. B Appl., vol. 9, no. 26, 2013.

[3] A. Sadegheih, P. R. Drake, D. Li, and S. Sribenjachot, "Global supply chain management under the carbon emission trading program using mixed integer programming and genetic algorithm,” 2011.

[4] S. A. MirHassani and H. F. Jahromi, “Scheduling multi-product tree-structure pipelines,” Comput. Chem. Eng., vol. 35, no. 1, pp. 165-176, 2011. 
[5] R. Rejowski Jr and J. M. Pinto, “Scheduling of a multiproduct pipeline system,” Comput. Chem. Eng., vol. 27, no. 8-9, pp. 1229-1246, 2003.

[6] R. Rejowski Jr and J. M. Pinto, “Efficient MILP formulations and valid cuts for multiproduct pipeline scheduling,” Comput. Chem. Eng., vol. 28, no. 8, pp. 1511-1528, 2004.

[7] R. Rejowski Jr and J. M. Pinto, "A novel continuous time representation for the scheduling of pipeline systems with pumping yield rate constraints,” Comput. Chem. Eng., vol. 32, no. 4-5, pp. 1042-1066, 2008.

[8] D. C. Cafaro and J. Cerdá, "Optimal scheduling of multiproduct pipeline systems using a non-discrete MILP formulation,” Comput. Chem. Eng., vol. 28, no. 10, pp. 2053-2068, 2004.

[9] D. C. Cafaro and J. Cerdá, "Rigorous scheduling of mesh-structure refined petroleum pipeline networks," Comput. Chem. Eng., vol. 38, pp. 185-203, 2012.

[10] Y. Liang, M. Li, and J. Li, “Hydraulic model optimization of a multi-product pipeline,” Pet. Sci., vol. 9, no. 4, pp. 521-526, 2012.

[11] S. Relvas, A. P. F. D. Barbosa-Póvoa, and H. A. Matos, "Heuristic batch sequencing on a multiproduct oil distribution system,” Comput. Chem. Eng., vol. 33, no. 3, pp. 712-730, 2009.

[12] M. Roegiers and B. Zhmud, "Property blending relationships for binary mixtures of mineral oil and elektrionised vegetable oil: viscosity, solvent power, and seal compatibility index,” Lubr. Sci., vol. 23, no. 6, pp. 263-278, 2011. 


\section{ABBREVIATION}

\begin{tabular}{|c|c|}
\hline Symbol & Abbreviation \\
\hline$v \mathrm{i}$ & the kinematic viscosity in centistokes (cst.) \\
\hline $\mathrm{X}$ & $\begin{array}{l}\text { the mass fraction (i.e., } \% \div 100 \text { ) of each component of the blend. In using the above } \\
\text { blending }\end{array}$ \\
\hline Ai & the internal area of the pipe in $\left(\mathrm{m}^{2}\right)$ \\
\hline $\mathrm{D}$ & the internal diameter of the pipe in (m). \\
\hline $\mathrm{U}$ & the velocity, by which the fluid transports, in (m/sec). \\
\hline $\mathrm{L}$ & the length of pipeline in (m). \\
\hline $\mathrm{C}$ & the interface length in (m). \\
\hline $\mathrm{V}$ & the interface volume in $\left(\mathrm{m}^{3}\right)$ \\
\hline hf & the head loss due to friction (SI units: m). \\
\hline $\mathrm{D}$ & $\begin{array}{l}\text { the hydraulic diameter of the pipe (for a pipe of circular section, this equals the internal } \\
\text { diameter of the pipe (m). }\end{array}$ \\
\hline $\mathrm{U}$ & $\begin{array}{l}\text { the average velocity of the fluid flow, equal to the volumetric flow rate per unit cross- } \\
\text { sectional wetted area I m/s). }\end{array}$ \\
\hline g & the local acceleration due to gravity $\left(\mathrm{m} / \mathrm{s}^{2}\right)$ \\
\hline $\mathrm{f}_{\mathrm{d}} \mathrm{a}$ & $\begin{array}{l}\text { dimensionless coefficient called the Darcy friction factor. It can be found from a Moody } \\
\text { diagram or more precisely by solving the Colebrook equation. }\end{array}$ \\
\hline$\frac{\varepsilon}{\mathrm{D}}$ & relative surface roughness \\
\hline $\mathrm{Hf}$ & the losses due to frictions \\
\hline $\mathrm{Hm}$ & the minor losses due to valves, bends, elbows ..... etc. \\
\hline Hs & the suction head \\
\hline
\end{tabular}

